\title{
A ORGANIZAÇÃO ECONÔMICA DOS PRODUTORES DE MEL ASSOCIADOS À APISMAR (RS): UMA AVALIAÇÃO A PARTIR DO MODELO ECD
}

\author{
ECONOMIC ORGANIZATION OF PRODUCERS OF HONEY \\ ASSOCIATED THE APISMAR (RS): AN EVALUATION FROM \\ MODEL ECD
}

João Carlos Coelho Junior

Universidade Estadual do Rio Grande do Sul - RS - Brasil

Pascoal José Marion Filho

Universidade Federal de Santa Maria - RS - Brasil

\begin{abstract}
Resumo: A pesquisa visa determinar a organização econômica dos produtores de mel associados à Associação de Apicultores de Santa Maria - APISMAR (RS). Utiliza-se o modelo Estrutura-CondutaDesempenho - ECD como referencial teórico e o método descritivo de análise, a partir de dados primários, obtidos por questionários estruturados e entrevista, e secundários. Os resultados da pesquisa mostram que entre os associados predomina a produção de mel em pequenas propriedades (de 1 a 5 ha), os apicultores estão há vários anos na atividade (em média, 16,7 anos), concentram-se no estrato de 1 a 50 colmeias e a maioria deles utiliza tecnologia manual na extração do produto. Em relação à organização econômica, os produtores não diversificam a produção, não diferenciam o produto e consideraram como principal barreira à entrada a difícil comercialização do mel. As principais condutas são: prática de preços pela média do mercado, redução de custos, reuniões de incentivo ao consumo de mel com a comunidade e entrega do produto a domić́lio. A produtividade média dos associados foi de $27 \mathrm{~kg} / \mathrm{colmeia} /$ ano e no Estado de $18 \mathrm{~kg} /$ colmeia/ano, um desempenho $50 \%$ superior.
\end{abstract}

Palavras-chave: Mel. Modelo Estrutura-Conduta-Desempenho. Organização Econômica.

Abstract: The research aims to determine the economic organization of the honey producers associated the APISMAR (RS). It is used the model Structure-Conduct-Performance (SCP) as referential theoretical and the descriptive method of analysis, based on primary data, obtained by structured questionnaires and interviews, and secondary. The survey results show that, among the associates, honey production prevails on small farms (1-5 ha), beekeepers are several years in the activity (average, 16.7 years), are concentrated in the extract from 1 to 50 beehives and the most of them use technology manual for extraction of the product. Regarding the economic organization, the producers do not diversify production, do not differentiate the product and considered the difficult for selling honey as main barrier to entering in market. The main conducts are: practice the average market price, cost reduction, community meetings to encourage the consumption of honey and product delivery at home. The average productivity of the associates was $27 \mathrm{~kg} /$ hive / year and in the State of $18 \mathrm{~kg} /$ hive / year, a $50 \%$ higher performance.

Keywords: Honey, model structure-conduct-performance, economic organization.

\section{Introdução}

Em 1996, existiam no Brasil 177.488 estabelecimentos agropecuários que desenvolviam a atividade apícola, com 1,6 milhões de colmeias e produção de 18.450 toneladas de mel. Em 2006, o número de estabelecimentos caiu para 95.939, o que representa uma redução de $46 \%$. Em compensação, a produção 
aumentou de 18.450 toneladas/ano para 36.193 toneladas/ano, ou seja, teve um crescimento de 95\% no período de 10 anos (IBGE, 2011).

Apesar de toda essa evolução na produção de mel, o Brasil ainda ocupa uma posição intermediária no contexto mundial. Segundo FAO (2011), no ano de 2005, a produção total de mel no mundo chegou a 1,38 milhões de toneladas, movimentando valores financeiros na casa de 1,5 bilhões de dólares. No mundo, cerca de 130 países desenvolvem atividades apícolas, destacando-se na produção: China, (22,1\% da produção mundial), Estados Unidos (5,9\%), Argentina (5,8\%), Turquia (5,4\%), Ucrânia (4,4\%), México (4,1\%), Rússia (3,8\%) e Índia $(3,8 \%)$. Esse bloco de países produz $50 \%$ do volume mundial de mel. No mesmo ano, o Brasil ocupava a $15^{\circ}$ posição do ranking.

No ano de 2007, conforme dados do IBGE (2011), a produção de mel no Brasil foi de 34.747 toneladas. Desse total, os três estados do Sul - Paraná, Santa Catarina e Rio Grande do Sul - produziram 16 mil toneladas.

O Rio Grande do Sul é responsável por $48 \%$ da produção de mel da região Sul, ou seja, 7.364 toneladas por ano, números bem acima do Estado do Paraná, segundo maior produtor da região, com 4.632 toneladas por ano.

Considerando os dados de 2008 do IBGE (2011), a produção de mel, no Brasil aumentou, aproximadamente, 8,7\% em relação ao ano anterior. Levando em conta a produção apenas do Rio Grande do Sul, a mesma cresceu em torno de $0,5 \%$, atingindo 7.418 toneladas.

Conforme Lengler et al. (2007), os apicultores frequentemente estão organizados em formas associativas, seja em associações e ou cooperativas. Segundo Confederação Brasileira de Apicultura - CBA, existem, no Brasil em funcionamento, 21 federações estaduais de apicultores e mais de 350 associações de apicultores em âmbito municipal ou regional, todas elas filiadas à CBA.

Para Lengler (2008a), as associações são o alicerce da apicultura no Brasil, pois o processo associativo oferece aos apicultores a possibilidade de vender o mel de maneira mais organizada e com menor dificuldade. No âmbito mundial, a Apimondia (International Federation of Beekeepers' Associations and other organisations working within the apiculture) é o "órgão máximo da apicultura" e possuí cerca de 5 milhões de membros em todo o mundo, distribuídos em 49 países (LENGLER et al., 2007, p. 158).

O Rio Grande do Sul possui a mais antiga federação de apicultores do Brasil e uma das maiores do País, a Federação de Apicultores do Rio Grande do Sul FARGS, com cerca de 73 associações de apicultores, 3 cooperativas e 40 empresas filiadas (LENGLER et al., 2007). Segundo a Secretaria de Comércio Exterior do Ministério do Desenvolvimento, Indústria e Comércio - MDIC, no Estado havia duas empresas habilitadas à exportação de mel in natura em 2010, sendo que o valor estimado das vendas de cada uma delas para o exterior supera um milhão de reais (MDIC, 2011). Pode-se destacar, ainda, segundo SEBRAE (2011), que o Estado possui cerca de 400 mil colmeias, com uma produtividade média de 17,89 $\mathrm{kg} /$ ano e, aproximadamente, 27 mil apicultores.

A APISMAR agrega 64 produtores de mel da região, sendo mais de $90 \%$ agricultores-apicultores, ou seja, eles não se dedicam exclusivamente à atividade apícola. Esse grupo de associados atua de forma colaborativa, caracteriza-se pela 
produção tradicional e utiliza tecnologia manual de extração. Anualmente, a produção gira em torno de 40 toneladas de mel.

Portanto, o Rio Grande do Sul tem a maior produção de mel do País e tradição no associativismo, o que justifica a pesquisa na região. O maior conhecimento sobre o sistema de produção e de comercialização contribui para a definição de políticas públicas e empresariais, visando maior eficiência, renda e bem-estar social. Para entender melhor o setor no Estado, tem-se como objetivo de pesquisa determinar a organização econômica dos produtores apícolas associados à APISMAR.

O artigo está organizado em quatro seções, sendo a primeira delas a presente introdução. A segunda seção apresenta o modelo ECD e a metodologia da pesquisa. A terceira seção traz a análise dos resultados sobre a organização econômica dos apicultores associados à APISMAR, ou seja, a estrutura, a conduta e o desempenho. E, por fim, na quarta seção, apresentam-se as conclusões do estudo.

\section{O modelo estrutura-conduta-desempenho (ECD)}

Originalmente, o modelo ECD foi desenvolvido para estudar o poder de mercado da indústria, sendo a política de preços explicada pela organização econômica das empresas. Entretanto, com pequenas adaptações, essa abordagem pode ser utilizada na análise de qualquer setor da economia ou segmento da cadeia de produção. A seguir, apresenta-se a teoria voltada para o setor industrial, como foi originalmente concebida.

A gênese do modelo "estrutura-conduta-desempenho" é atribuída a Edward S. Mason (1939) e a seus colegas de Harvard. A motivação foi a descrença na eficácia da teoria neoclássica dos preços para explicar aspectos do comportamento industrial, muito importante naquele momento para auxiliar na elaboração da política antitruste norte-americana. No entanto, segundo Schmalensee (1982), foi Joe Bain, na década de 1950, quem iniciou a formalização teórica do modelo ECD.

Segundo Schmalensee (1992), nos primeiros trabalhos de Bain, as pesquisas empíricas sobre a organização da indústria envolviam estudos de caso detalhados de indústrias selecionadas, e visavam identificar, especialmente, relações entre concentração de vendedores, condições de entrada na indústria e lucratividade.

A partir dos anos 1960, os estudos sobre Organização Industrial - OI passaram a ser feitos entre indústrias, com dados cross-section e técnicas estatísticas. A evolução teórica continuou nos anos 1970 e 1980, com a incorporação no modelo de variáveis de conduta, condições de mercado e políticas governamentais.

O sentido de causalidade entre as variáveis do modelo ECD também foi mudando através do tempo. No início, as versões mais tradicionais consideravam o sentido de causalidade unidirecional (seguindo da estrutura para o desempenho), sendo a estrutura determinada exogenamente. As versões mais modernas do modelo abandonaram o sentido de causalidade unidirecional e tratam as estruturas de mercado como sendo endogenamente determinadas. 
Isso pode ser constatado em Scherer e Ross (1990), que enfatizam que nem todas as influências seguem das condições básicas e da estrutura de mercado para o desempenho. Citam, como exemplo, o efeito de esforços intensos em pesquisa e desenvolvimento - P\&D variável da conduta, que pode alterar a tecnologia das indústrias $e$, em consequência, suas estruturas de custos e/ou grau de diferenciação do produto. Ainda, a política de preços dos vendedores (variável da conduta) pode encorajar a entrada ou saída de firmas do mercado, transformando a estrutura.

Farina (1996, p.10) afirma que, "embora se admita que haja efeitos retroativos da conduta das empresas e de seu desempenho sobre as mesmas condições básicas e sobre a estrutura, a relação causal fica estabelecida da estrutura para o desempenho, especialmente no curto prazo".

São pequenas as diferenças entre os autores de Organização Industrial quanto à inclusão de variáveis no modelo ECD e a relação de causalidade entre elas. Neste artigo, o modelo adotado é o mesmo apresentado por Carlton e Perloff (1990) e já utilizado por diversos autores, entre eles: Zaeyen (1986), Aguiar (1994), Moraes (1996), Garcia (1997), Marion Filho (1997) e Dalla Corte (2008).

Essa é uma visão mais moderna do modelo, resultado de intensos debates visando aprimorá-lo, principalmente após a realização de vários trabalhos empíricos. Possas (1990) comenta que esse tipo de abordagem privilegia os aspectos estruturais do mercado e tem incorporado de Bain a sugestão de tomar a concentração como elemento básico da estrutura. Essa ênfase na concentração tem origem na própria concepção do modelo, pois o mesmo admitia, desde o princípio, uma relação inversa entre concentração e concorrência.

Bain (1968) enfatiza que embora a concentração seja o aspecto da estrutura da indústria mais frequentemente enfocado, há outras dimensões da estrutura que também são importantes, como a condição de entrada de novos vendedores potenciais na indústria e o grau de diferenciação do produto dentro da mesma.

Segundo Carlton e Perloff (1990, p.348), a barreira à entrada de novos vendedores na indústria é um dos mais importantes fatores determinantes da estrutura e do desempenho. Com relação a isso, comentam que "em indústrias com significantes barreiras à entrada, no longo prazo, os preços podem permanecer acima do nível competitivo".

As barreiras à entrada citadas com maior frequência na literatura econômica são: economias de escala, necessidade de capital, acesso aos canais de distribuição, desvantagens de custos independentes de escala, produto diferenciado e política governamental. Esta última barreira à entrada pode resultar da concessão, por parte do governo, da exploração de uma atividade a um pequeno grupo de empresários, ou até mesmo pelo estabelecimento de um grande número de exigências para explorá-la, inibindo a entrada de novos vendedores.

Segundo Caves (1967, p.58), "a diferenciação de produtos existe quando os consumidores revelam preferências diferentes entre marcas individuais de um produto". Essa é uma variável importante no estudo da estrutura da indústria, uma vez que indica o poder que o fabricante tem sobre o produto comercializado. Já o grau de diferenciação física do produto deve ser entendido como o número de 
diferentes produtos colocados à venda pelos produtores. A diferenciação física do produto ajuda no estabelecimento de preferências diferentes por parte do consumidor. Segundo Kon (1994, p.87-88), "a diferenciação de um produto diz respeito à introdução, na gama de produtos de uma empresa, de uma nova mercadoria que tenha a característica de ser substituta próxima de outra anteriormente por ela produzida, e que será comercializada em seus mercados". A autora comenta que a diferenciação pode resultar de uma mudança na natureza do produto, na forma de apresentação, particularidades do desenho, cor, estilo, melhoria na qualidade, por marcas registradas ou marcas industriais que adquirem uma conotação de prestígio.

Além da concentração, das condições de entrada na indústria e do grau de diferenciação do produto, acrescenta-se a integração vertical e a diversificação da produção para explicar a estrutura de uma indústria.

A integração vertical poderá ser para trás, em direção à fonte de matériaprima do produto gerado pela empresa, ou para frente, em direção ao varejo. Pode afetar a concorrência na indústria por meio das economias de escala (pela utilização de recursos ociosos) e pela necessidade de capital. Entretanto, a integração vertical também pode ser utilizada como uma estratégia da empresa em relação, por exemplo, ao fornecimento de matéria-prima.

A diversificação da produção, segundo Kon (1994, p.91), ocorre pela "[...] introdução de um produto em um mercado no qual a firma ainda não participa [...]". Portanto, a diversificação aumenta a variedade de bens finais produzidos. A diversificação da produção de uma empresa poderá ocorrer dentro da mesma indústria, quando o produtor passa a oferecer várias linhas de produtos ou quando a empresa passa a gerar produtos em outras indústrias. A sua adoção poderá resultar em economias de escala e escopo para a empresa, tornando-a mais competitiva.

A diferenciação e a diversificação são variáveis distintas da estrutura de uma indústria, e não precisam ocorrer simultaneamente. Uma indústria pode diferenciar seus produtos sem diversificar sua produção, enquanto outra indústria pode diversificar sua produção sem se preocupar em diferenciar seus produtos em cada linha de produção.

Do exposto acima, verifica-se que a estrutura da indústria varia com a concentração, a diferenciação do produto, as barreiras à entrada, a diversificação da produção e a integração vertical. Por isso, Possas (1990) argumenta ser simplista tipificar uma estrutura se for desconsiderado parte dessas variáveis. De outro lado, Garcia (1997, p.52) comenta que:

Os conceitos de estrutura de mercado em concorrência perfeita, concorrência monopolística, oligopólio e monopólio descritos pela teoria microeconômica tradicional podem, sem dúvida, orientar a descrição das indústrias e mercados, mas exigem certas modificações principalmente quando se pretende identificar e medir poder de mercado.

A conduta dos empresários de uma indústria com relação aos gastos com propaganda/promoção (para alterar as preferências dos consumidores) e P\&D (visando criar novos produtos e processos), o modo de fixação dos preços para os 
seus produtos, o montante de investimentos feito nas empresas, a ocorrência de fusões, acordos e contratos entre os empresários com a finalidade de aumentar o poder de mercado pode ser determinada ou não pela estrutura da indústria. Mais especificamente sobre a propaganda, Sutton (1992) comenta que o nível de propaganda já foi utilizado como uma barreira à entrada em vários estudos, já que ela também busca a diferenciação do produto.

As empresas de uma indústria podem ter o seu desempenho avaliado a partir da eficiência produtiva e alocativa, pela qualidade do produto elaborado, por meio do progresso técnico, e pelos lucros obtidos durante determinado período. Dentro da nova abordagem da ECD, o desempenho não é necessariamente determinado pela estrutura e pela conduta, mas, também, pode vir a determinálas. A eficiência econômica das empresas pode fazer com elas sejam grandes, o que eleva a concentração e altera a estrutura da indústria.

O modelo ECD também deixa claro que a estrutura, a conduta e o desempenho não só são afetados pelas condições básicas de oferta (tecnologia, matéria-prima, durabilidade do produto, localização das fábricas, economia de escala, economia de escopo e sindicalização dos produtores), demanda (elasticidade-preço da demanda, bens substitutos, taxas de crescimento da demanda, sazonalidade da demanda, localização da demanda, aglomeração de pedidos e método de compra) e pela política governamental, como também são responsáveis por mudanças nas mesmas.

As políticas governamentais podem afetar diretamente a indústria por meio de políticas específicas para o setor (regulamentação, leis antitruste, impostos, incentivos ao investimento, incentivos ao emprego, entre outras) ou indiretamente, meio da política macroeconômica (política fiscal, política monetária e política cambial, por exemplo).

\section{Metodologia e coleta de dados}

Esta pesquisa se caracteriza como sendo descritiva e exploratória. Segundo Gil (2002), a pesquisa exploratória tem como principal objetivo proporcionar maior compreensão do fenômeno objeto de pesquisa, permitindo, assim, uma melhor definição do problema de pesquisa. Já a pesquisa descritiva tem como principal característica a descrição do fenômeno ou o estabelecimento de relação entre as variáveis. Segundo Roesch (2005), a pesquisa descritiva também tem a preocupação de descrever as características de um grupo, a exemplo dos apicultores associados à APISMAR.

As variáveis do modelo ECD utilizadas na análise da produção de mel são: diversificação na produção, diferenciação do produto e barreiras à entrada (para a análise da estrutura); tecnologia utilizada na produção, capacidade de produção e destino da produção (condições básicas da oferta e da demanda); fixação de preços, estratégia de custos, desenvolvimento de produtos e estratégias de mercado, como distribuição da produção e controle de qualidade (conduta); e a produtividade dos apicultores (desempenho). 
Os dados utilizados na análise foram obtidos a partir de questionários aplicados junto aos apicultores associados à APISMAR, no período de janeiro a março de 2011. Cabe salientar que alguns resultados da pesquisa de campo foram confrontados com o banco de dados da APISMAR, como por exemplo, a quantidade produzida por cada um dos associados, tipo de flora predominante nas propriedades etc.

Responderam ao questionário 63 apicultores, de um total de 64 produtores cadastrados na APISMAR. Além disso, fez-se uma entrevista com o presidente da APISMAR, Silvio Lengler, em junho de 2011, com a finalidade de obter uma visão mais global a respeito da atividade apícola dos associados e do mercado de mel.

Os dados secundários foram obtidos por meio de pesquisa nas seguintes fontes: IBGE, CBA e Brasil Apícola, APISMAR, Associação Brasileira dos Exportadores de Mel - $A B M E L$, entidades parceiras, Serviço Brasileiro de apoio às Micro e Pequenas Empresas - SEBRAE, Ministério da Agricultura, Pecuária e Abastecimento - MAPA, Ministério do Desenvolvimento Agrário - MDA, Ministério do Desenvolvimento, Indústria e Comércio Exterior - MDIC e Organização das Nações Unidas para Alimentação e Agricultura - FAO.

\section{A organização dos produtores de mel da APISMAR}

\subsection{0 perfil dos apicultores}

\subsubsection{Características gerais dos produtores}

O tempo médio na atividade apícola dos associados à APISMAR é de 16,7 anos, sendo que 9 apicultores estão na atividade a menos de 10 anos, 38 estão de 10 a 19 anos, 10 estão de 20 a 29 anos e 6 estão a mais de 30 anos produzindo mel. Portanto, constata-se que $86 \%$ dos apicultores pesquisados estão há mais de 10 anos na apicultura.

Uma característica da produção de mel é de que ela pode ser feita dentro de uma área reduzida ou ser realizada em várias. Na definição do perfil dos produtores, verificou-se que 55 apicultores possuem propriedade com estrato entre 1 e 5 hectares; 4 têm propriedade entre 6 e 11 hectares; e 4 informaram que não possuem propriedade rural, mas desenvolvem a atividade apícola através do arrendamento de terra. Logo, diante de tal constatação, pode-se afirmar que, na sua grande maioria, os produtores de mel desenvolvem as suas atividades em pequenas propriedades.

O estudo de Fleck e Belinaso (2008), sobre a cadeia do mel e derivados da região central do Rio Grande do Sul, menciona a existência de dois tipos de apicultores: "agricultores-apicultores" e "apicultores da cidade". No primeiro grupo, encontram-se os agricultores que diversificam as suas atividades na propriedade e atuam com pequena escala de produção (com até 50 colmeias). Já o segundo grupo se caracteriza por ter ocupação fora da agricultura (empresários, 
profissionais liberais e outros) e morar nos centros urbanos. Este último grupo trabalha com uma escala maior de produção, mais de 50 colmeias.

No caso da APISMAR, dos 63 apicultores entrevistados, 58 são apicultores da cidade e 5 são agricultores-apicultores. Entre os apicultores da cidade, 30 informaram que são profissionais liberais/autônomos, 16 são empresários, 9 são funcionários públicos e 8 são aposentados.

Portanto, os dados analisados mostram que as principais características dos apicultores associados à APISMAR são: (i) não dedicação exclusiva à produção de mel, possuem outras atividades profissionais; (ii) estão há muitos anos na atividade apícola, a maioria produz mel há mais de 10 anos; e, (iii) produzem mel em pequenas propriedades, a moda está entre 1 e 5 hectares. Assim, os produtores pertencentes à pesquisa podem ser considerados antigos na atividade, uma vez que o número de apicultores praticamente dobrou nos últimos 10 anos no Brasil (DESER, 2011).

\subsubsection{A tecnologia utilizada na produção de mel}

O estudo se limitou a identificar duas etapas do processo, a utilizada na produção ou cultivo (tradicional ou orgânica) e na extração do mel (mecânica ou manual). Em relação ao cultivo, verificou-se que 55 apicultores $(87,30 \%$ ) utilizam o tradicional e 8 informaram ter o cultivo orgânico. Segundo o presidente da APISMAR, Silvio Lengler, a produção orgânica de mel informada pelos apicultores está ligada à origem, pois, em algumas propriedades, em determinada época do ano, não existem lavouras próximas, o que leva os produtores a considerá-lo como sendo orgânico. Para o entrevistado, isso decorre da falta de informação, pelo fato desse processo ser ainda incipiente no Brasil e pelo alto custo para implantar apiários orgânicos. Portanto, tecnicamente, a produção é toda tradicional.

O resultado corrobora com os trabalhos de Tomaselli (1999), Harkaly (2000) e Schafaschek (2005), os quais relatam que a legislação sobre a produção orgânica ainda está sendo desenvolvida no Brasil e que o País está se utilizando das normas europeias para determinar se o mel é ou não orgânico.

Com relação à flora utilizada pelas abelhas, constatou-se que em $76 \%$ das propriedades predomina o "mato nativo" (incluindo as flores do campo), composto de espécies oriundas da região. Também se destacam as matas de eucalipto, presentes em $24 \%$ das propriedades rurais.

Sobre o tipo de abelha utilizada pelos apicultores, 100\% dos respondentes informaram que utilizam as africanizadas, o que está de acordo com as pesquisas de Lengler (2008), Gonçalves (2006), Fleck e Belinaso (2008) e EMBRAPA (2010).

$\mathrm{Na}$ extração do mel, alguns trabalhos [entre eles: Soriani (2002), Lengler (2008) e Fleck e Belinaso (2008)] relatam que existem dois tipos de tecnologias, a mecânica e a manual. Na pesquisa, constatou-se que 52 dos 63 respondentes $(82,54 \%$ dos produtores) utilizam a tecnologia manual durante o processo da retirada do mel dos favos. Portanto, 11 apicultores extraem o mel mecanicamente, mais comum na produção em grande escala. 
Na entrevista, Silvio Lengler menciona que a extração mecânica do mel é realizada, em alguns casos, com centrífuga elétrica. Ainda segundo o entrevistado, a Associação possui uma centrifuga e uma laminadora de cera, que podem ser utilizadas pelos apicultores para realizar a extração do mel em suas propriedades e fazer o preparo das colmeias. Lengler destacou, também, que, após a extração do mel na propriedade, os associados podem utilizar a estrutura da Associação para as demais etapas do processo de produção.

\subsection{A organização econômica dos apicultores}

\subsubsection{Políticas Governamentais}

O setor apícola brasileiro é regulamentada por leis federais, estaduais e municipais, sendo que, conforme o MAPA, o marco inicial foi a publicação do Regulamento da Inspeção Industrial e Sanitária de Produtos de Origem Animal RISPOA em 1952, o qual estabelece normas para a produção de carnes, lácteos, pescados e apícolas. Segundo Regis (2003), somente no ano de 1962 ocorreu a primeira revisão do RISPOA.

Em 1985, foram desenvolvidas normas higiênico-sanitárias e tecnológicas para a produção de mel, cera de abelhas e derivados. A Portaria SIPA n 006/85 tem como finalidade regulamentar e esclarecer algumas falhas dos documentos anteriores em relação aos produtos apícolas. Em 1997, o governo brasileiro publicou a Portaria no 367/97, que traz a regulamentação técnica e a exigência sobre identidade e qualidade do mel, obedecendo as normas aprovadas pelo Mercado Comum do Sul - MERCOSUL. No ano 2000, a mesma foi revisada e republicada como Instrução Normativa $n^{\circ} 3$, em vigor até hoje.

Ao analisar os dados obtidos na pesquisa de campo, constatou-se que as mudanças nas regulamentações e nas normas técnicas foi o item que gerou maior impacto entre os produtores (média 4,51), relatado por 22 deles $(34,92 \%$ ) (Tabela 1). Pode-se justificar a escolha dessa opção pela frequente necessidade que os apicultores têm de se adequar às exigências estabelecidas pelos órgãos fiscalizadores.

Tabela 1. Efeitos sentidos pelos apicultores em relação às políticas governamentais (notas de 0 a 5, quanto maior a nota, maior o efeito sentido pelo apicultor)

\begin{tabular}{l|c}
\hline \multicolumn{1}{c|}{ Efeitos sentidos pelo apicultor } & Média \\
\hline Mudanças na regulamentação e normas técnicas & 4,51 \\
Restrição de crédito e taxas de juros & 4,12 \\
Mudanças de alíquotas de impostos sobre o produto & 3,91 \\
Alterações na política cambial & 3,44 \\
Outras: Falta de incentivo para atividade apícola. & 3,15 \\
\hline
\end{tabular}

Fonte: Elaborada pelos autores a partir dos dados da pesquisa de campo. 
Também ficou evidente que a restrição de crédito e taxas de juros, com média 4,12, é sentida pela maioria dos produtores. Acontece que os apicultores precisam fazer investimentos, colher e comercializar a produção, assim como outros produtores agrícolas, mas não recebem o mesmo tratamento.

Segundo Lengler (entrevistado), a Associação auxilia os apicultores a produzir em conformidade com a legislação vigente, para que quando ocorra a fiscalização, o produto esteja adequado às normas técnicas para produção de mel.

\subsubsection{A estrutura da produção de mel}

a) Barreiras à entrada percebida pelos apicultores

Uma das principais dificuldades enfrentadas pelos apicultores é a colocação do mel no mercado. Segundo Fleck e Belinaso (2008), esse problema é muito comum na produção apícola, tanto na venda de forma organizada, por meio de entrepostos legalizados e de associação de apicultores, como na venda fracionada e direta (Tabela 2).

Tabela 2. Barreiras à entrada de novos produtores no mercado (notas de 0 a 5 , quanto maior a nota, maior a barreira à entrada)

\begin{tabular}{l|c}
\hline Barreira à entrada & Média \\
\hline Dificuldades em colocar o produto no mercado & 4,95 \\
Quantidade mínima de produção & 4,08 \\
Exigência de mão de obra especializada & 3,92 \\
Valor do investimento inicial & 3,42 \\
Acesso à tecnologia de produção de mel (máquinas) & 3,00 \\
Dificuldades na obtenção de matéria-prima (cera, caixa,...) & 2,17 \\
Outros (falta de incentivos do governo, concorrência, pouco & 1,88 \\
conhecimento do setor) & \\
\hline
\end{tabular}

Fonte: Elaborada pelos autores a partir dos dados da pesquisa de campo.

A dificuldade enfrentada na hora de escoar a produção do mel limita a renda dos produtores e faz com que alguns deles deixem de acreditar na atividade apícola. A segunda barreira à entrada mais importante é a quantidade mínima de produção, a qual pode ser explicada pelo desinteresse dos compradores por pequena quantidade.

O terceiro item mais lembrado foi a exigência de mão de obra especializada, ou seja, com conhecimento sobre o processo de produzir mel. Algumas atividades nas colmeias são extremamente importantes e cansativas, já que são realizadas manualmente e envolvem riscos, despertando pouco interesse das pessoas, tornando escassa a mão de obra.

b) Diferenciação do produto e diversificação da produção 
$\mathrm{Na}$ produção apícola existem diferente tipos de produtos, como própolis, geleia real, cera e mel. A pesquisa de campo revelou que não existe diversificação de produtos, uma vez que $100 \%$ dos pesquisados produzem exclusivamente mel. Entretanto, deve-se destacar que a apicultura é uma entre tantas atividades presentes nas propriedades, normalmente com produção diversificada, e que nem sempre é a atividade principal. Essa questão ficou evidente na pesquisa, pois a maioria dos respondentes $(76,19 \%)$ confirmou a diversidade econômica, contra $17,46 \%$ que afirmaram ser a única atividade geradora de renda.

Dentre os apicultores que informaram realizar também "outras atividades" econômicas na propriedade, 47 citaram pequenos cultivos: cana-de-açúcar, feijão, milho, entre outros. A criação de gado de corte ocorre em 12; o cultivo de arroz em 9; e a produção de soja em 6 propriedades. Um proprietário informou que possui um entreposto de mel, o qual compra e recebe mel de outros apicultores.

Os apicultores também responderam sobre a contribuição das atividades da propriedade na renda ${ }^{1}$. Analisando as respostas, verifica-se que no grupo de proprietários que possuem pequenos cultivos, o mel representa um complemento de renda de até $30 \%$. Por sua vez, os apicultores que possuem, na sua propriedade, cultivos de soja e arroz, o mel representa entre 5\% e 10\% da renda. De um modo geral, os associados à APISMAR consideraram a renda do mel importante no orçamento (92,06\% deles), o que está de acordo com o resultado da pesquisa de Fleck e Belinaso (2008).

A diferenciação do mel ocorre pelo tipo de floração (eucalipto, laranjeira etc.) ou com a adição de sabores, como, por exemplo: hortelã, laranja, entre outros. Em relação ao processo de diferenciação, Lengler (entrevistado) destacou que o MAPA permite a classificação do mel em três tipos, segundo a sua origem: mel de eucalipto, flores do campo e flora silvestre (mata nativa). Também informou que essa classificação não é feita pelos apicultores associados à APISMAR, pois os lotes não são controlados na origem e, por isso, "pode haver mistura de vários tipos de floras em um único lote".

\subsubsection{A conduta (estratégias) dos apicultores}

O modelo ECD descreve que a conduta depende da estrutura dos produtores, especialmente no curto prazo. Nesse subitem, a conduta adotada pelos apicultores é avaliada com base no desenvolvimento de novos produtos, estratégias de mercado, fixação de preços e acordos entre os produtores.

a) Desenvolvimento de novos produtos e estratégias de mercado

\footnotetext{
${ }^{1}$ Considera-se renda as receitas geradas por atividades realizadas na propriedade.
} 
$\mathrm{Na}$ entrevista, Lengler mencionou que existem estratégias para aumentar as vendas, as quais são implementadas por meio de cursos junto aos associados e à comunidade. Nos encontros, são mostrados os benefícios de ter o mel na dieta das pessoas, o que estimula o consumo direto, e são vendidos produtos que contêm o mel como ingrediente principal, gerando um aumento na utilização do mesmo como matéria-prima.

A conduta dos apicultores em relação ao mercado foi avaliada a partir de ações propostas na pesquisa e da informação gerada na questão em aberto. Assim, identificou-se que 32 apicultores $(50,79 \%)$ utilizam como estratégia a redução de custos de produção, 18 informaram que procuram diferenciar o seu produto dos demais concorrentes por intermédio de ações simples, como por exemplo, entregar o produto na casa do cliente; 12 não têm estratégia e 01 produtor mencionou que busca o aumento de produtividade como estratégia. Ao realizar o cruzamento das informações, percebeu-se que este produtor pertence ao grupo dos grandes apicultores e que ele concentra as vendas nas agroindústrias.

Os demais apicultores, identificados na pesquisa como diferenciando o seu produto/serviço dos demais concorrentes (18 apicultores), utilizam como estratégia o controle de qualidade no processo produtivo. Esses fazem a extração do mel em suas propriedades e seguem as normas estabelecidas pela APISMAR. A etapa final do processo é realizada na Associação.

b) Fixação de preços do mel

A definição do preço do mel é uma estratégia importante na venda do produto, já que o mesmo é de difícil diferenciação visual. Na pesquisa de campo, os apicultores se posicionaram de forma diferente em relação ao preço de venda, ou seja, 49 (77,78\%) informaram que o preço é igual à média do mercado; 07 negociam o preço; e 07 praticam um preço abaixo da média de mercado.

Os apicultores que negociam o preço do mel fazem parte do grupo de produtores que vendem direto para a agroindústria. Como, frequentemente, essas agroindústrias exportam mel in natura, o preço pago ao apicultor segue o preço internacional do produto.

No entanto, Lengler mencionou na entrevista que em assembleia é definido um preço mínimo (ou de referência) para os associados venderem o mel ao consumidor final. Nas vendas para o atacado ou para a agroindústria a negociação é livre. Essa informação vem ao encontro da pesquisa e justifica os resultados apresentados no subitem em relação à prática de preços pela média do mercado.

A afirmação de Lengler sobre a orientação em relação ao preço de venda foi confirmada pela maioria dos produtores, uma vez que $55(87,30 \%)$ dos apicultores confirmaram a existência de um acordo para o preço mínimo do mel em Santa Maria e essa prática ocorre há vários anos. Os demais 08 (12,70\%) não confirmaram a existência do mesmo. 
O desempenho dos associados à APISMAR na atividade apícola é avaliado a partir da produção de mel por ano e da produtividade média por caixa de abelha/ano (colmeia). Na tabela 3, verifica-se que 21 apicultores produziram acima de $1.000 \mathrm{Kg}$ de mel no ano de 2009. Vale destacar que, entre eles, dois produziram mais de $7.500 \mathrm{~kg}$. Com base nos dados dos associados, a produção total de mel foi de $89.885 \mathrm{Kg}$ em 3.337 colmeias.

Tabela 3. Número de produtores por estrato de produção de mel, em 2009

\begin{tabular}{lc}
\hline \multicolumn{1}{c|}{ Produção de mel } & Número de produtores \\
\hline Até $50 \mathrm{~kg}$ & 04 \\
Entre 51 e $200 \mathrm{~kg}$ & 12 \\
Entre 201 e $500 \mathrm{~kg}$ & 14 \\
Entre 501 e $1.000 \mathrm{~kg}$ & 12 \\
Acima de $1.000 \mathrm{~kg}$ & 21 \\
\hline Total & 63 \\
\hline
\end{tabular}

Fonte: Elaborada pelos autores a partir dos dados da APISMAR.

A maioria dos associados $(73,02 \%)$ está no grupo de apicultores que tem de 1 a 50 colmeias. Os demais têm entre 51 a 200 colmeias (20,63\%) e 6,35\% produzem com mais de 200 colmeias. De acordo com a classificação proposta em DESER (2011), os apicultores do primeiro grupo utilizam a renda do mel como complementar, pois têm outras atividades profissionais ou fonte de renda.

Em relação à produtividade de mel, verifica-se na tabela 4 que ela é de $26,85 \mathrm{~kg} /$ colmeia/ano. Segundo Lengler (presidente da APISMAR), ela varia entre 15 e $40 \mathrm{Kg}$ e depende muito do cuidado que cada apicultor tem com sua colmeia.

Tabela 4. Produtividade por colmeia/ano por estrato em 2009

\begin{tabular}{|c|c|c|c|c|}
\hline Estratos de colmeias & $\begin{array}{c}\mathrm{N}^{\circ} \text { de } \\
\text { apicultores }\end{array}$ & $\begin{array}{l}N^{\circ} \text { total de } \\
\text { colmeias }\end{array}$ & $\begin{array}{l}\text { Produção anual } \\
(\mathrm{kg})\end{array}$ & $\begin{array}{l}\text { Produtividade Média } \\
\text { (kg/colmeia/ano) }\end{array}$ \\
\hline De 1 a 50 colmeias & 46 & 975 & 23255 & 24 \\
\hline De 51 a 200 colmeias & 13 & 1312 & 33230 & 25 \\
\hline De 201 a 500 colmeias & 4 & 1060 & 33400 & 32 \\
\hline Total & 63 & 3347 & 89885 & 27 \\
\hline
\end{tabular}

Fonte: Elaborada pelos autores com dados da APISMAR.

Os apicultores que estão no estrato de 1 a 50 colmeias obtiveram, no ano de 2009, uma produtividade média de 24 quilos de mel por colmeia/ano, os de 51 a 200 colmeias alcançaram uma produtividade de $25 \mathrm{~kg}$ e os que possuem entre 
201 e 500 colmeias obtiveram uma produtividade de $32 \mathrm{Kg}$. Portanto, a produtividade cresce com a escala de produção e com a especialização.

Rocha, Guarienti e Lara (2011) analisaram a produção de mel no Rio Grande do Sul e constataram que a média histórica de produtividade é 15 $\mathrm{kg} /$ colmeia/ano, enquanto que a nacional é de $12,5 \mathrm{~kg} /$ colmeia/ano, o que mostra que a produtividade no Estado é superior à brasileira. Estabelecendo um comparativo entre a produtividade de mel da APISMAR e a do Rio Grande do Sul em 2009, tem-se para o Estado, aproximadamente, $18 \mathrm{Kg}$ de mel por colmeia/ano e para os associados, $27 \mathrm{Kg}$ por colmeia/ano, o que representa uma produtividade média $50 \%$ superior.

Dos $89.885 \mathrm{Kg}$ de mel produzidos pela APISMAR, segundo Lengler, 13.482 $\mathrm{Kg}(15 \%)$ foram destinados à exportação. O restante $(76.403 \mathrm{Kg})$ foi vendido no mercado nacional. Além disso, o entrevistado informou que o mel produzido pelos associados tem grande aceitação em Porto Alegre-RS e a maior parte da produção é vendida em Santa Maria-RS, seja para o consumidor final, varejo ou atacado.

Os resultados dos questionários ratificam as afirmações do presidente da APISMAR, pois 30 produtores $(47,62 \%)$ informaram que vendem sua produção exclusivamente para o consumidor final local e $33(52,38 \%)$ apicultores comercializam a sua produção tanto para o consumidor final quanto para o varejo, atacado e agroindústrias.

Em relação à venda para o varejo, a mesma ocorre, em sua grande maioria, de forma consignada, ou seja, os apicultores deixam o produto em pequenos estabelecimentos (padarias, mercearias etc.) e recebem o valor do produto quando a venda ocorre. Se a comercialização demora a acontecer o produto é retirado, reprocessado e colocado à venda novamente.

Dos 63 apicultores, 13 informaram que concentram as suas vendas no atacado e para agroindústrias (entrepostos). Nesse caso, o destino da produção é a exportação e o mercado de Porto Alegre. Esses produtores extraem mais de 1.000 $\mathrm{Kg} /$ ano e não enfrentam problemas para vender a sua produção, pois o foco não é o consumidor final.

No entanto, na entrevista Lengler relatou que durante o embargo do mel brasileiro pela União Europeia houve maior dificuldade na venda do produto, pois havia forte oferta e o consumo é baixo no País. Isso ficou comprovado na pesquisa de Fleck e Belinaso (2008), pois 25\% dos respondentes (de um total de 318) "nunca consomem" mel, em Ribeirão Preto (SP) e Cachoeira do Sul (RS). Ainda, conforme o entrevistado, logo que o embargo terminou, o quadro se normalizou, pois os apicultores que vendem para outras regiões e para o mercado externo têm por hábito comprar o mel dos demais produtores.

\section{Conclusões}

A pesquisa tem como objetivo determinar a organização econômica dos apicultores associados à APISMAR, no Rio Grande do Sul, a partir do modelo ECD. Preliminarmente, verificou-se que os apicultores associados à APISMAR se 
caracterizam por exercer outras atividades econômicas, além da apicultura; desenvolvem a produção de mel há vários anos, a maioria produz há mais de 10 anos; atuam em pequenas propriedades, a moda de propriedade está entre 1 e 5 hectares; fazem o cultivo tradicional do mel, com predominância da flora tipo mato nativo; e utilizam tecnologia manual na extração do produto.

A partir das variáveis do modelo ECD, pode-se concluir, em relação às políticas governamentais, que as mudanças nas regulamentações e nas normas técnicas foram as mais sentidas pelos apicultores. Em relação à estrutura, constatou-se que os produtores de mel não diversificam a produção e não diferenciam o produto. No entanto, a propriedade tem uma produção diversificada, com soja, arroz, gado de corte entre outros. Ainda, a principal barreira à entrada foi considerada a dificuldade de colocar o produto no mercado, ou seja, escoar a produção.

As principais estratégias adotadas pelos apicultores são a redução de custos de produção e a adoção de uma política de preços que segue a média do mercado. Outras ações também foram detectadas, como a venda direta, com entrega na casa do cliente, e reuniões com a comunidade para divulgar os benefícios do mel e a sua utilização como matéria-prima na elaboração de vários produtos.

Em relação ao desempenho, constatou-se que a produtividade média dos associados supera a do Estado em 50\%. Em 2009, a produtividade média do Rio Grande do Sul ficou próxima de $18 \mathrm{~kg} /$ colmeia/ano e entre os associados 27 $\mathrm{kg} /$ colmeia/ano. A performance melhor dos associados é atribuída à especialização conseguida através do apoio da Associação e do tempo na atividade.

Finalizando, pode-se perceber que a APISMAR exerce um papel importante na geração de renda dos seus integrantes, na sua grande maioria pequenos agricultores, especialmente, como facilitadora na produção, centro de informação e difusora de conhecimento sobre como produzir de acordo com as normas e utilizar o mel. Com isso, contribui para o desenvolvimento regional e para melhorar o bem-estar das famílias que incorporaram a atividade apícola. Além disso, mostra-se como uma alternativa viável para futuras políticas públicas que visam ampliar a renda familiar.

\section{REFERÊNCIAS}

AGUIAR, D. R. D. A indústria de esmagamento de soja no Brasil: mudança estrutural, conduta e alguns indicadores de desempenho. Revista de Economia $e$ Sociologia Rural, v. 32, n.1, p.23-46, jan./mar. 1994.

BAIN, J. Industrial organization, 2.ed. New York: John Wiley, 1968. 678p.

CARLTON, B.; PERLOFF, J. Modern industrial organization. Harper Collins, 1990.

CAVES, R. E; PORTER, M. E. Fron entry barriers to mobility barriers: conjectual decisions and contrived deterrence to new competition. Quarterly Journal of Economics, v. 99, n.2, p. 241-261, Cambridge, May, 1967. 
DALLA CORTE, V. F. As estratégias e a organização das indústrias de farinha de trigo e de massas alimentícias do Rio Grande do Sul. Santa Maria, 2008. 114p. Dissertação (Mestrado) - Programa de Pós-Graduação em Administração, Universidade Federal de Santa Maria.

DESER - Departamento de Estudos Socioeconômicos Rurais. Disponível em: < www.deser.org.br > Acesso em: jun. 2011.

EMBRAPA - Empresa Brasileira de Pesquisa Agropecuária: disponível em: < http://sistemasdeprodução.cnptia.embrapa.br > Acesso em: jun. 2010.

FAO. Food and Agriculture Organization. Disponível em: < www.fao.org > Satatistical databes. Acesso em: abr. 2011.

FARINA, E. M. M.Q. Reflexões sobre desregulamentação e sistemas agroindústrias: a experiência brasileira. São Paulo, 1996, Tese de livre docência (Doutorado) - Faculdade de Economia, Administração e Contabilidade. Universidade de São Paulo - USP.

FONTENELE, A. M. Das análises de Bain à teoria dos mercados contestáveis: uma inversão metodológica na construção de um Modelo-Síntese. Estudos Econômicos, São Paulo, v.26, n.3, p.382-409, set/dez. 1996.

FLECK, L. F.; BELINASO, J.A. Estudo da cadeia do mel e derivados no território central do RS. MDA/SDT, 2008.

GARCIA, L. A. F. A organização industrial da moagem de trigo no Brasil. Piracicaba, 1997. 158p. Dissertação (Mestrado) - Escola Superior de Agricultura Luiz de Queiroz, Universidade de São Paulo.

GIL. A. C. Técnicas de pesquisa em economia e elaboração de monografias. 4. ed. São Paulo: Atlas, 2002.

GONÇALVES, L. S. 50 anos de abelhas africanizadas no Brasil. In: XVI Congresso Brasileiro de Apicultura e // Congresso Brasileiro de Meliponicultura. Aracaju - SE, Congressos, Seminários e Encontros Brasileiros de Apicultura, $4^{\mathrm{a}}$ ed. CD-ROM, 2006.

HARKALY, A. Mel e produtos apícolas (mel) orgânico no Brasil. In: Congresso Brasileiro de Apicultura, 12. 2000. Florianópolis. Anais... Florianópolis, 2000. CDROM.

IBGE. Censo Agropecuário. Disponível em: < www.ibge.gov.br $>$ Acesso em: mar. 2011.

KON, A. Economia Industrial. São Paulo: Nobel, 1994. 
LENGLER, L. Uma análise do comportamento empreendedor e do processo decisional de presidentes de associações apícolas no Rio Grande do Sul. Revista Administração UFSM, v.1, n.1, p. 153-170, Jan-Abr, 2008a.

LENGLER, L. Sustentabilidade, empreendedorismo e cooperação em associações de apicultores gaúchos: uma análise dos gestores - associados. Porto Alegre, 2008. 148p. Dissertação (Mestrado) - Programa de Pós-Graduação em Agronegócios do Centro de Pesquisas em Agronegócios, Universidade Federal do Rio Grande do Sul.

LENGLER, L.; LAGO, A. CORONEL, D. A. A organização associativa no setor apícola: contribuições e potencialidades. Organizações Rurais e Agroindustriais, v. 9, n. 2 p. 151-163, 2007.

MARION FILHO, P. J. A evolução e a organização recente da indústria de móveis nos estados de Santa Catarina e Rio Grande do Sul. Piracicaba, 1997. 151p. Tese (Doutorado) - Escola Superior de Agricultura Luiz de Queiroz, Universidade de São Paulo.

MASON, E. S. Price and production policies of large-scale enterprise. American Economic Review, v. 29, n.1, p.61-74, 1939.

MINISTÉRIO DO DESENVOLVIMENTO INDÚSTRIA E COMÉRICO EXTERIOR MDIC. Estatística de exportação e importação de mel natural. Disponível em: < http://www.aliceweb.mdic.gov.br > Acesso em: jun. 2011.

MINISTÉRIO DA AGRICULTURA, PECUÁRIA E ABASTECIMENTO - MAPA. Estatísticas. Disponível em: < http://www.agricultura.gov.br >. Acesso em: jun. 2011.

MORAES, M. A. F. D. A indústria de madeira preservada no Brasil: um estudo de sua organização industrial. Piracicaba, 1996. 154p. Dissertação (Mestrado) Escola Superior de Agricultura Luiz de Queiroz, Universidade de São Paulo.

POSSAS, M. L. Estrutura de mercado em oligopólio. São Paulo: Hucitec, 1990.

ROCHA, H. C.; GUARIENTI, I.; LARA, A. A. A Produção de Mel no Planalto Médio Riograndense. Disponível em: www.apacame.org.br. Acesso em: jun. 2011.

ROESCH, S. M. A. Projeto de estágio e de pesquisa em administração: guia para estágios, trabalhos de conclusões, dissertações e estudos de caso. 3.ed. São Paulo: Atlas, 2005.

SEBRAE - Serviço Brasileiro de Apoio a Micro e Pequena Empresa. Disponível em: $<$ www.sebrae.com.br > acesso em: jun. 2011. 
SORIANI, F. Legislação de produtos apícolas. In: Congresso Brasileiro de Apicultura. 14. 2002. Campo Grande. Anais... Campo Grande: [s.n]. 2002, CDRom.

SUTTON, J. Sunk costs and market structure. The Mit Press, 1992.

SCHAFASCHEK, R. T. Do convencional ao ecológico: normas, divergências e implicações sobre a produção apícola. Florianópolis, 2005. 92p. Dissertação (Mestrado) - Programa de Pós-Graduação em Agroecossistemas do Centro de Ciências Agrárias, Universidade Federal de Santa Catariana. Florianópolis, 2005.

SCHERER, F. M.; ROSS, D. Industrial Market structure and economic performance. 3. ed. Chicago: Rand McNally \& Co, 1990.

SCHMALENSEE, R. The new industrial organization and the ecoonomic analysis of modern markets. In: HILDEBRAND, ed. Advances in economic theory. Cambridge: University Press, 1982. p.253-285.

TOMASELLI, A. Produção de mel à base de essenciais nativas com selo ecológico. Informativo Zum Zum, v.33, n. 291, p. 6-7, Florianópolis, 1999.

ZAEYEN, A. Estrutura e desempenho do setor de papel e celulose no Brasil. Rio de Janeiro, 1986. 99p. Dissertação (Mestrado) - Instituto de Economia Industrial, Universidade Federal do Rio de Janeiro.

Submetido em 01/08/2012

Aprovado em 20/04/2015

\section{Sobre os autores \\ João Carlos Coelho Junior}

Mestrado em Administração na Universidade Federal de Santa Maria (UFSM). Professor da Universidade Estadual do Rio Grande do Sul (UERGS) - Campus Santana do Livramento.

Endereço: Rua Rivadávia Corrêa - 825, Centro. 97573011 - Sant'Ana do Livramento, RS - Brasil.

E-mail: adm_joaojr@hotmail.com

\section{Pascoal José Marion Filho}

Doutorado em Economia Aplicada pela Escola Superior de Agricultura Luiz de Queiroz (ESALQ/ USP). Professor da Universidade Federal de Santa Maria (UFSM).

Endereço: Rua Marechal Floriano Peixoto, 1750 - $6^{\circ}$ Andar (sala 603), Centro. 97015372 - Santa Maria, RS - Brasil.

E-mail: pascoaljmarion@yahoo.com.br 